\title{
Effect of processing method of cereals on feed intake, eating behaviour, rumination and nutrient digestibility in nyala antelope (Tragelaphus angasii)
}

\author{
M. Przybyło', J. Kański', O. Lasek', A. Kloska² and P. Górka ${ }^{1,3}$ \\ ${ }^{1}$ University of Agriculture in Krakow, Faculty of Animal Science, Department of Animal Nutrition and Dietetics \\ al. Mickiewicza 24/28, 30-059 Kraków, Poland \\ ${ }^{2}$ Silesian Zoological Garden, Promenada gen. Jerzego Ziętka 7, 41-501 Chorzów, Poland
}

KEY WORDS: grinding, pelleting, steamflaking, zoological gardens, ruminants, intermediate feeder

Received: 20 March 2018

Revised: $\quad 30$ May 2018

Accepted: 24 August 2018

${ }^{3}$ Corresponding author:

e-mail: p.gorka@ur.krakow.pl

\begin{abstract}
The aim of the study was to determine the effect of processing method of cereals used in the diet for nyala antelope (Tragelaphus angasii) on feed intake, eating behaviour, rumination and nutrient digestibility. The study was conducted according to Latin square design $(4 \times 4)$ on four adult nyala males. The animals were fed a basal diet consisting of a mixture of cereals (maize, wheat and oat), vegetables and fruits $(1.25 \mathrm{~kg} /$ day), chopped dehydrated lucerne $(0.5 \mathrm{~kg} / \mathrm{day})$ and meadow hay (ad libitum). Experimental treatments differed in processing method of cereals offered in the basal diet: 1. finely ground (GR); 2. steam-flaked (SF); or pelleted to obtain: 3 . small ( $6 \mathrm{~mm}$ diameter size; SP) or 4. large (12 $\mathrm{mm}$ diameter size; LP) pellet. Feed intake did not differ between the treatments. Eating time of basal diet was longer for $\mathrm{GR}$ in comparison to SF and SP $(P<0.01)$, and also longer for $L P$ in comparison to $S P(P=0.05)$, with a maximum difference between treatments of $11 \mathrm{~min} /$ day. Eating rate ( $\mathrm{g}$ dry matter/min) of basal diet was slower for $\mathrm{GR}$ in comparison to SF and SP $(P \leq 0.02)$. Consumption of meadow hay and chopped lucerne was not affected by cereal processing method. Digestibility of acid detergent fibre was greater $(P=0.05)$ and digestibility of dry matter and neutral detergent fibre tended $(P \leq 0.08)$ to be greater for GR than for SP. It can be concluded that, processing method of cereals may affect feeding behaviour of zoo ruminants.
\end{abstract}

\section{Introduction}

Although the use of cereal-based feeds in diets for wild captive ruminants should be avoided, cereal grains may account for over $50 \%$ of dry matter consumed by some zoo ruminants (Schilcher et al., 2013; Gattiker et al., 2014; Górka et al., 2016; Przybyło et al., 2017). In most cases cereal grains are still used in the diets for zoo ruminants due to historical tradition. However, this historical tradition and associated habits of zookeepers are often difficult to change.
Besides unreasonably high intake of concentrates, our previous studies showed a negative impact of pelleted cereal-based feed on feed intake and nutrient digestibility in sitatunga (Tragelaphus spekii) and addax (Addax nasomaculatus) antelopes (Górka et al., 2016; Przybyło et al., 2017). Results of mentioned studies and a very high intake of concentrates by nyala antelope (Tragelaphus angasii) in the present study initiated many changes in the composition of diets for ruminants in the Silesian Zoological Garden. Prior to these changes, however, different 
processing methods of cereals were tested to propose a physical structure of concentrates that would at least partially limit the negative consequences of their excessive feeding to ruminants, still practiced in some zoological gardens. Independently of difficulties in convincing zookeepers for changing traditional diets and not using cereal grains for zoo ruminants at all, this study was justified by the fact that in some circumstances provision of cereal-based feed may be even necessary, at least periodically. For example, due to a lack of other more appropriate sources of nutrients, or their only seasonal availability that is often dependent on whether conditions.

In this study we hypothesized that flaked or ground cereals are better option for wild captive ruminants then pelleted cereals. Although cereals can be subjected to various processing methods prior to feeding, such as grinding, flaking or pelleting, the latter one is the most often used processing of cerealbased feeds for wild captive ruminants (Clauss and Dierenfeld, 2008; McCusker et al., 2011; Schilcher et al., 2013). This is mostly due to easier storage and handling of pelleted feed. However, pelleted feed is eaten faster and less frequently than not pelleted feed (e.g., ground concentrates; Górka et al., 2016) and pelleting increases the fermentation rate of starch in the rumen, due to starch gelatinization during the pelleting process (Bertipaglia et al. 2010; Razzaghi et al., 2016). This can increase the postprandial shortchain fatty acids concentration in the rumen and ruminal digesta acidity (Castrillo et al., 2013; Górka et al., 2015; Razzaghi et al., 2016); the latter having many negative consequences for the animal (Plaizier et al., 2008; Schilcher et al., 2013). To support this view, cereal-based feed in our previous studies was shown to decrease nutrient digestibility (especially digestibility of fibre) and feed intake when compared to a non-pelleted feed of similar nutrient composition in sitatunga and addax antelopes (Górka et al., 2016; Przybyło et al., 2017). Furthermore, due to the selective feeding behaviour of many ruminant species e.g., selective intake of plant parts, the use of pelleted feed may further limit the already greatly limited expression of their natural behavioural needs in captivity (Van Soest, 1996).

In contrast to pelleted cereal-based feed, ground cereals are eaten at a slower rate than pelleted ones (at least when mixed with fruits and vegetables; Górka et al., 2016) and grinding does not lead to starch gelatinization and associated more rapid starch fermentation in the rumen (Bertipaglia et al. 2010; Razzaghi et al., 2016). On the other hand, flaking of cereals offers an opportunity for selective intake of diet components, especially when a mixture of different pelleted cereals is fed, and thus may at least partially contribute to better coverage of natural behavioural needs of at least some ruminant species in captivity; however, when feed is properly balanced the selective intake may lead to deficient or excessive intake of nutrients, and, therefore, may be considered also as negative. Nevertheless, grinding or flaking could be potentially better options for processing of cereals for captive ruminants.

In the present study, the effect of grinding, steamflaking and pelleting of cereals on feed intake, eating behaviour, rumination and nutrient digestibility in nyala antelope was investigated. The nyala is an intermediate feeding ruminant consuming mainly dicots, but fruits may account for even up to one third of the natural diet (Gagnon and Chew, 2000). Nutrition of browsing and also intermediate feeding ruminants is considered as especially difficult due to often reluctant consumption of structured feeds that leads to high proportion of unstructured feeds in the diet, in many cases cereals (Clauss et al., 2003; Taylor et al., 2013; Górka et al., 2016). Access to four adult males of nyala in the Silesian Zoological Garden (Poland) gave a unique opportunity to investigate practical aspects of feeding this species.

\section{Material and methods}

\section{Animals, diets and experimental design}

The study was conducted in Silesian Zoological Garden (Chorzów, Poland) from January to March 2016. Four adult male nyala antelopes (2.5 to 5 years old) were used in the study. Through the whole study animals were kept and maintained according to standard procedures adopted at the Silesian Zoological Garden during the winter season, with only minor modifications for the purposes of the study. Antelopes were housed in individual pens $(2 \times 3 \mathrm{~m})$ in a building equipped with an automatic climate controlling system. Pens were bedded with wood shavings each day, except during the faecal collection period when the bedding was not applied to avoid contamination of faeces. The temperature in the building was set at $21^{\circ} \mathrm{C}$ and the lighting regime provided light during 12 hours.

The study was carried out as $4 \times 4$ Latin square design. Each experimental period consisted of 10 days of diet adaptation and 5 days of data collection. Although relatively short, the adaptation period was considered sufficient, due to lack of substantial differences in ingredient (and chemical) 
Table 1. Chemical composition of feeds

\begin{tabular}{|c|c|c|c|c|c|c|}
\hline Nutrient & $\begin{array}{l}\text { Dry matter (DM), } \\
\%\end{array}$ & $\begin{array}{l}\text { Crude ash, } \\
\% \text { DM }\end{array}$ & $\begin{array}{l}\text { Organic matter, } \\
\% \text { DM }\end{array}$ & $\begin{array}{l}\text { Crude protein, } \\
\% \text { DM }\end{array}$ & $\begin{array}{l}\mathrm{NDF}^{1}, \\
\% \mathrm{DM}\end{array}$ & $\begin{array}{l}\mathrm{ADF}^{2} \\
\% \mathrm{DM}\end{array}$ \\
\hline \multicolumn{7}{|l|}{ Cereals $^{3}$} \\
\hline ground & $90.3 \pm 0.3$ & $2.5 \pm 0.0$ & $97.5 \pm 0.02$ & $12.89 \pm 0.29$ & $13.7 \pm 0.65$ & $6.4 \pm 0.61$ \\
\hline steam flaked & $90.1 \pm 0.4$ & $1.8 \pm 0.1$ & $98.2 \pm 0.12$ & $12.21 \pm 0.39$ & $17.0 \pm 1.30$ & $7.3 \pm 0.09$ \\
\hline \multicolumn{7}{|l|}{ pelleted } \\
\hline small pellet ${ }^{4}$ & $89.4 \pm 0.26$ & $2.5 \pm 0.0$ & $97.5 \pm 0.11$ & $13.0 \pm 0.34$ & $17.1 \pm 0.80$ & $7.1 \pm 0.68$ \\
\hline large pellet ${ }^{5}$ & $90.4 \pm 0.45$ & $2.5 \pm 0.1$ & $97.5 \pm 0.01$ & $13.0 \pm 0.08$ & $16.9 \pm 0.45$ & $7.4 \pm 0.41$ \\
\hline Pellet with marker ${ }^{6}$ & $89.9 \pm 0.60$ & $4.9 \pm 0.1$ & $95.1 \pm 0.14$ & $13.0 \pm 0.09$ & $14.6 \pm 0.80$ & $6.6 \pm 0.23$ \\
\hline Apple & $15.1 \pm 0.59$ & $2.4 \pm 0.2$ & $97.6 \pm 0.24$ & $3.8 \pm 0.27$ & $11.8 \pm 0.67$ & $9.4 \pm 0.38$ \\
\hline Carrot & $12.7 \pm 0.83$ & $5.3 \pm 0.5$ & $94.7 \pm 0.45$ & $9.7 \pm 1.62$ & $13.6 \pm 0.79$ & $14.4 \pm 1.02$ \\
\hline Beetroot & $13.9 \pm 1.02$ & $8.0 \pm 0.9$ & $92.0 \pm 0.92$ & $16.1 \pm 0.69$ & $13.3 \pm 1.64$ & $8.0 \pm 0.70$ \\
\hline Meadow hay & $90.3 \pm 0.76$ & $6.0 \pm 1.3$ & $94.0 \pm 1.26$ & $8.1 \pm 1.96$ & $64.2 \pm 1.55$ & $38.6 \pm 1.03$ \\
\hline Chopped dehydrated lucerne & $91.8 \pm 0.29$ & $9.0 \pm 0.3$ & $91.0 \pm 0.30$ & $16.1 \pm 0.42$ & $44.2 \pm 1.81$ & $35.8 \pm 1.46$ \\
\hline
\end{tabular}

${ }^{1} \mathrm{NDF}$ - neutral detergent fibre; ${ }^{2} \mathrm{ADF}$ - acid detergent fibre; ${ }^{3} 35 \%$ of maize, $35 \%$ of wheat and $30 \%$ of oat (as fed); ${ }^{4} 6 \mathrm{~mm}$ diameter size; ${ }^{5} 12 \mathrm{~mm}$ diameter size; ${ }^{6} 34 \%$ of maize, $34 \%$ of wheat, $30 \%$ of oat and $2 \%$ of $\mathrm{Cr}_{2} \mathrm{O}_{3}$ (as fed); mean $\pm \mathrm{SD} ; n=4$ periods

composition of the diets between treatments. The length of adaptation period was also determined by the limited period of time when all animals allocated to the study were kept in individual pens and were available for the study in the Silesian Zoo.

Through the whole study antelopes were fed diet that resembled a standard diet used for nyala in Silesian Zoological Garden, consisting of a basal diet [a mixture of cereals ( $35 \%$ of maize, $35 \%$ of wheat and $30 \%$ of oat; as fed), fruits and vegetables], chopped dehydrated lucerne and meadow hay (Tables 1 and 2). This diet was changed soon after the study by reducing the amount of concentrates

Table 2. Ingredient and chemical composition of basal diets

\begin{tabular}{|c|c|c|c|c|}
\hline \multirow{2}{*}{ Indices } & \multicolumn{4}{|c|}{ Treatment $^{1}$} \\
\hline & GR & SF & SP & LP \\
\hline \multicolumn{5}{|c|}{ Ingredient composition ${ }^{2}, \mathrm{~kg} /$ day } \\
\hline cereals & 0.75 & 0.75 & 0.75 & 0.75 \\
\hline pellet with marker & 0.05 & 0.05 & 0.05 & 0.05 \\
\hline apple & 0.20 & 0.20 & 0.20 & 0.20 \\
\hline carrot & 0.20 & 0.20 & 0.20 & 0.20 \\
\hline beetroot & 0.10 & 0.10 & 0.10 & 0.10 \\
\hline \multicolumn{5}{|l|}{ Chemical composition ${ }^{3}$} \\
\hline dry matter (DM), \% & $60.9 \pm 0.3$ & $60.8 \pm 0.5$ & $60.4 \pm 0.4$ & $60.9 \pm 0.5$ \\
\hline organic matter, \% DM & $97.2 \pm 0.1$ & $97.7 \pm 0.1$ & $97.2 \pm 0.1$ & $97.1 \pm 0.1$ \\
\hline crude ash, \% DM & $2.8 \pm 0.1$ & $2.3 \pm 0.1$ & $2.9 \pm 0.1$ & $2.9 \pm 0.1$ \\
\hline crude protein, \% DM & $12.5 \pm 0.3$ & $11.9 \pm 0.4$ & $12.6 \pm 0.3$ & $12.5 \pm 0.1$ \\
\hline $\mathrm{NDF}^{4}, \% \mathrm{DM}$ & $13.7 \pm 0.5$ & $16.5 \pm 1.1$ & $16.6 \pm 0.7$ & $16.7 \pm 0.5$ \\
\hline $\mathrm{ADF}^{5}, \% \mathrm{DM}$ & $6.8 \pm 0.5$ & $7.6 \pm 0.1$ & $7.4 \pm 0.6$ & $7.8 \pm 0.2$ \\
\hline \multicolumn{5}{|c|}{$\begin{array}{l}{ }^{1} \mathrm{GR} \text { - ground cereals, SF - steam-flaked cereals, SP - pelleted cere- } \\
\text { als (small pellet; } 6 \mathrm{~mm} \text { diameter size), LP - pelleted cereals (large } \\
\text { pellet; } 12 \mathrm{~mm} \text { diameter size); }{ }^{2} \text { on top of the basal diet animals were } \\
\text { fed } 0.50 \mathrm{~kg} / \text { day of chopped dehydrated lucerne and meadow hay for } \\
\text { ad libitum consumption; }{ }^{3} \mathrm{n}=4 \text { periods; }{ }^{4} \mathrm{NDF} \text { - neutral detergent fibre; } \\
{ }^{5} \mathrm{ADF} \text { - acid detergent fibre }\end{array}$} \\
\hline
\end{tabular}

fed to the animals. Experimental treatments differed in processing method of cereals offered in the basal diet that were: 1 . finely ground (GR); 2 . steam-flaked (SF); or pelleted to obtain: 3. small (6 mm diameter size; $\mathrm{SP}$ ) or 4. large (12 mm diameter size; LP) pellet (Figure 1). GR cereals were ground to pass through a $3-\mathrm{mm}$ screen and then mixed thoroughly. SP and LP cereals were ground as GR, put into conditioner chamber (steamed with $150{ }^{\circ} \mathrm{C}$ to bring material temperature to $55-60^{\circ} \mathrm{C}$ ) for $3 \mathrm{~min}$ and then pressed through $6-\mathrm{mm}$ or $12-\mathrm{mm}$ diameter size matrix (70-80 ${ }^{\circ} \mathrm{C}$ at pelleting) for SP and LP, respectively. In order to obtain SF, whole cereal grains were treated by steam $\left(150^{\circ} \mathrm{C}\right)$ for $3 \mathrm{~min}$ and flaked when the temperature of the material dropped to $60-70^{\circ} \mathrm{C}$.

Prior to feeding, $0.75 \mathrm{~kg}$ of GR, SF, SP or LP was mixed with chopped fresh carrots $(0.2 \mathrm{~kg})$, apples $(0.2 \mathrm{~kg})$, beetroots $(0.1 \mathrm{~kg})$ and $0.05 \mathrm{~kg}$ of pellet containing chromium oxide, to form a basal diet. The pellet containing chromium oxide consisted of maize, wheat and oat in similar proportions to mixture of concentrates offered in the basal diet and additionally contained $2 \%$ of chromium oxide $\left(\mathrm{Cr}_{2} \mathrm{O}_{3}\right)$ that was used as a digesta marker. The above mentioned pellet accounted for $3.8 \%$ of the basal diet $[5.7 \%$ of basal diet dry matter (DM)] and was assumed as not affecting eating behaviour of the animals by interacting with GR, SF, SP or LP offered in the basal diet. Simultaneously, this method of digesta marker delivery resulted in its willing intake right after delivery. Each animal consumed daily $615 \pm 5.4 \mathrm{mg}($ mean $\pm \mathrm{SD})$ of $\mathrm{Cr}$. The basal diet was offered in a stone trough at 12:00. In most cases the basal diet was consumed by the animal in a period of $8-12 \mathrm{~h}$. Prior to basal diet feeding (10:00), $0.5 \mathrm{~kg}$ 


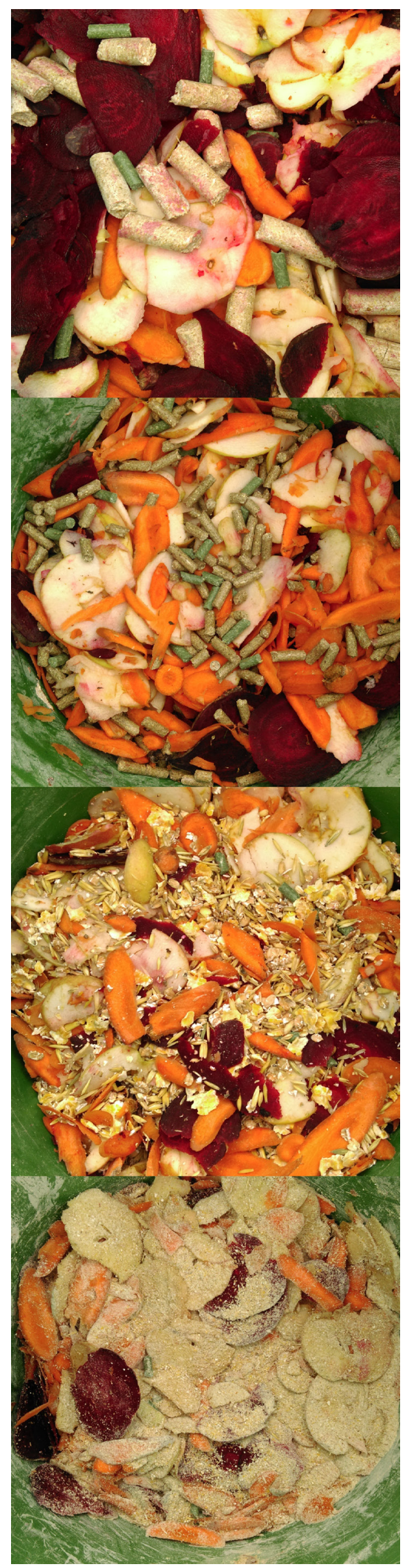

of chopped $(2-4 \mathrm{~cm})$ dehydrated lucerne was fed from plastic bucket and meadow hay was offered ad libitum from hay racks. The hay was refilled once every $24 \mathrm{~h}$.

\section{Sampling, analyses, calculation}

Intake of basal diet, chopped dehydrated lucerne and meadow hay was recorded daily. Representative samples of feeds were collected weekly (two samples per period) and stored at room temperature (concentrates, chopped dehydrated lucerne and hay) or frozen (fruits and vegetables; $-18{ }^{\circ} \mathrm{C}$ ). Weekly samples were composited by period to reflect diet composition in each period of the study. Refusals of basal diets, chopped dehydrated lucerne and representative samples of refusals of hay from the last 5 days of each experimental period were collected daily, weighed and kept frozen $\left(-18^{\circ} \mathrm{C}\right)$ for chemical composition analysis. Representative samples of faeces not contaminated with the urine $(100 \mathrm{~g} / \mathrm{d} /$ animal) were collected during the last 5 days of each experimental period and kept frozen $\left(-18^{\circ} \mathrm{C}\right)$ for further chemical analysis.

The chemical compositions of feeds, refusals and faeces were analysed as previously described by Górka et al. (2016). Chromium concentration in pellet containing $\mathrm{Cr}_{2} \mathrm{O}_{3}$, refusals of basal diet and faeces were analysed using flame atomic absorption spectrophotometry (PN-EN 1233:2000P). DM output in faeces was calculated by dividing $\mathrm{Cr}$ intake (mg/day) by $\mathrm{Cr}$ content in faeces ( $\mathrm{mg} / \mathrm{kg}$ of $\mathrm{DM})$, and subsequently DM intake and DM output was used to calculate apparent total tract digestibility.

Eating and rumination behaviour was recorded and summarized as previously described by Górka et al. (2016). Briefly, animals were recorded for $48 \mathrm{~h}$ in two consecutive days (days 11 and 12 of each experimental period), using a digital video recorder (model BCS-0404LE-AN, Dahua Technology Co., Hangzhou, China) equipped with 3 high resolution colour day/night video cameras (EVA-TV-1200iRW, KAM-TECH, Kraków, Poland; wide angle lens, $2.8-12 \mathrm{~mm}$ ). The recordings were saved on a hard disk (resolution $720 \times 576 \mathrm{px}$, D1) with 6 frames/s speed. The recordings were watched by one person, who summarized the number of feeding bouts and the times of eating and rumination for each animal and period. The feeding bout was considered when an animal put his head into the feeder, tub or started removing hay from a hay rack, and ended when the animal turned back and did not come back for at least 1 minute. Rumination was considered as a period when animal was ruminating (characteristic moves 
of jaw easy to recognize on the recording). On the basis of the episodes of eating, rumination and DM intake, eating time ( $\mathrm{min} /$ day), eating bouts ( $\mathrm{n} /$ day), eating time per episode $(\mathrm{min} / \mathrm{n})$ and eating rate $(\mathrm{g}$ $\mathrm{DM} / \mathrm{min}$ ), as well as rumination bouts (n/day) and rumination time ( $\mathrm{min} / \mathrm{day}, \mathrm{min} / \mathrm{n}$ and $\mathrm{min} / \mathrm{g} \mathrm{DM}$ ) were calculated. The eating rates were calculated by dividing DM intake by the time spent on eating or ruminating, respectively. Eating time and rate were calculated separately for the basal diet, chopped dehydrated lucerne and hay and then summarized as total eating time and rate.

\section{Statistical analyses}

Data were analysed as $4 \times 4$ Latin square design using the MIXED procedure of SAS (version 9.2, SAS Inst. Inc., Cary, NC, USA). The statistical model included treatment as fixed effects, and period and animal as random effects. For eating behaviour and rumination data, a mean from two days of observation was used for statistical analysis. Orthogonal contrasts (GR vs SF, GR vs SP and SP vs LP) were used to test for differences between treatments. Significance was declared at $P \leq 0.05$ and trends when $0.05<P \leq 0.10$.

\section{Results}

Chemical compositions of feeds and basal diets used in the study are presented in Tables 1 and 2. Although mixtures of cereals were prepared from the same batches of feeds, neutral detergent fibre (NDF) and acid detergent fibre (ADF) contents were lower in the mixture of ground cereals (from 3.2 to $3.3 \%$ and from 0.7 to $1.0 \%$ for NDF and ADF, respectively) in comparison to steam-flaked and pelleted cereals. As a result, NDF and ADF contents in the basal diet were lower for GR compared to other treatments (Table 2).

In the last period of the study one animal had to be transferred to the other zoological garden and thus data for this animal could not be collected. As a result, one observation for LP treatment was lacking in the data set.

Dry matter intake of the basal diet, hay, and total DM intake were not affected by cereal processing method, and chopped dehydrated lucerne was always completely consumed (Table 3 ); however, a ratio of actually consumed unstructured feeds (basal diet) to structured feeds (meadow hay and chopped dehydrated lucerne) was lower for GR in comparison to SF and SP $(P \leq 0.01)$ and tended $(P=0.10)$ to be lower for SP in comparison to LP, indicating a higher intake of structured feeds in these cases. Nutrient intake did not differ between treatments, except a tendency $(P \leq 0.08)$ for lower crude protein and crude ash intake for GR in comparison to SF and SP, respectively.

Eating time of the basal diet averaged $38 \mathrm{~min} /$ day. It was longer for GR in comparison to SF and SP $(P<0.01)$, and LP feeding resulted in longer eating time of basal diet than SP $(P=0.05$; Table 4$)$. The size of the pellet also affected the number of eating bouts (average 23 per day) that tended $(P=0.07)$ to be greater for SP in comparison to LP. Eating time of the basal diet per episode of eating averaged $1.7 \mathrm{~min} /$ bout, and was longer for GR than for SP $(P=0.01)$, not different between GR and SF, and shorter for SP in comparison to LP $(P=0.02)$. Eating rate of the basal diet averaged $20.9 \mathrm{~g} \mathrm{DM} /$ min, and was slower for GR in comparison to SF

Table 3. Effect of processing method of cereals on feed and nutrient intake

\begin{tabular}{|c|c|c|c|c|c|c|c|c|}
\hline \multirow{2}{*}{ Indices } & \multicolumn{4}{|c|}{ Treatment $^{1}$} & \multirow{2}{*}{$\mathrm{SE}^{2}$} & \multicolumn{3}{|l|}{ Contrast } \\
\hline & GR & SF & SP & LP & & GR vs SF & GR vs SP & SP vs LP \\
\hline \multicolumn{9}{|l|}{ Dry matter intake, kg/d } \\
\hline basal diet & 0.69 & 0.74 & 0.74 & 0.78 & 0.020 & 0.19 & 0.20 & 0.50 \\
\hline meadow hay & 0.43 & 0.38 & 0.40 & 0.40 & 0.046 & 0.16 & 0.37 & 0.95 \\
\hline $\begin{array}{l}\text { chopped dehydrated } \\
\text { lucerne }\end{array}$ & 0.46 & 0.46 & 0.46 & 0.46 & - & - & - & - \\
\hline total & 1.58 & 1.58 & 1.59 & 1.65 & 0.062 & 0.97 & 0.83 & 0.78 \\
\hline $\begin{array}{l}\text { Unstructured-to-structured } \\
\text { feed ratio }\end{array}$ & 0.79 & 0.92 & 0.88 & 0.93 & 0.033 & $<0.01$ & 0.01 & 0.10 \\
\hline \multicolumn{9}{|l|}{ Nutrient intake, g/d } \\
\hline organic matter & 1055 & 1051 & 1053 & 1131 & 56.6 & 0.71 & 0.75 & 0.40 \\
\hline crude ash & 81 & 84 & 83 & 82 & 4.3 & 0.13 & 0.06 & 0.87 \\
\hline crude protein & 128 & 131 & 128 & 129 & 5.9 & 0.08 & 0.22 & 0.93 \\
\hline $\mathrm{NDF}^{1}$ & 640 & 635 & 636 & 693 & 38.6 & 0.45 & 0.41 & 0.44 \\
\hline $\mathrm{ADF}^{1}$ & 425 & 423 & 426 & 463 & 23.2 & 0.85 & 0.92 & 0.81 \\
\hline
\end{tabular}

${ }^{1}$ see Table $2 ;{ }^{2}$ SE - standard error 
Table 4. Effect of processing method of cereals on eating behaviour and rumination

\begin{tabular}{|c|c|c|c|c|c|c|c|c|}
\hline \multirow{2}{*}{ Indices } & \multicolumn{4}{|c|}{ Treatment $^{1}$} & \multirow{2}{*}{$\mathrm{SE}^{2}$} & \multicolumn{3}{|l|}{ Contrast } \\
\hline & GR & SF & SP & LP & & GR vs SF & GR vs SP & SP vs LP \\
\hline \multicolumn{9}{|l|}{ Basal diet } \\
\hline eating time, min/day & 45 & 36 & 34 & 38 & 4.8 & $<0.01$ & $<0.01$ & 0.05 \\
\hline eating bouts, n/day & 23.0 & 21.5 & 27.0 & 19.8 & 4.01 & 0.59 & 0.22 & 0.07 \\
\hline eating time per bout, min & 2.01 & 1.82 & 1.24 & 1.95 & 0.138 & 0.39 & 0.01 & 0.02 \\
\hline eating rate, $\mathrm{g} \mathrm{DM}{ }^{3} / \mathrm{min}$ & 15.1 & 22.8 & 25.2 & 20.4 & 2.20 & 0.02 & 0.01 & 0.19 \\
\hline \multicolumn{9}{|l|}{ Meadow hay } \\
\hline eating time, min/day & 74 & 64 & 65 & 56 & 16.6 & 0.34 & 0.43 & 0.36 \\
\hline eating bouts, n/day & 30.5 & 26.8 & 29.5 & 32.4 & 7.42 & 0.60 & 0.91 & 0.67 \\
\hline eating time per bout, min & 2.59 & 2.28 & 2.18 & 1.76 & 0.180 & 0.34 & 0.32 & 0.27 \\
\hline eating rate, $g \mathrm{DM} / \mathrm{min}$ & 5.5 & 6.5 & 7.5 & 7.6 & 0.79 & 0.41 & 0.15 & 0.68 \\
\hline \multicolumn{9}{|l|}{ Chopped dehydrated lucerne } \\
\hline eating time, min/day & 38 & 42 & 38 & 40 & 6.2 & 0.43 & 0.83 & 0.53 \\
\hline eating bouts, n/day & 23.8 & 23.0 & 18.3 & 21.2 & 4.02 & 0.71 & 0.02 & 0.18 \\
\hline eating time per bout, min & 1.62 & 1.91 & 2.64 & 1.85 & 0.248 & 0.62 & 0.11 & 0.23 \\
\hline eating rate, g DM/min & 13.5 & 11.8 & 12.9 & 13.2 & 0.92 & 0.30 & 0.71 & 0.59 \\
\hline \multicolumn{9}{|l|}{ Total } \\
\hline eating time, min/day & 157 & 141 & 137 & 132 & 15.7 & 0.12 & 0.05 & 0.59 \\
\hline eating bouts, $n /$ day & 77.3 & 71.3 & 74.8 & 71.3 & 3.71 & 0.24 & 0.58 & 0.49 \\
\hline eating time per bout, min & 2.09 & 2.02 & 1.89 & 1.84 & 0.122 & 0.42 & 0.06 & 0.60 \\
\hline eating rate, $\mathrm{g} \mathrm{DM} / \mathrm{min}$ & 10.1 & 11.6 & 11.9 & 12.5 & 0.72 & 0.16 & 0.08 & 0.74 \\
\hline \multicolumn{9}{|l|}{ Rumination } \\
\hline bouts, n/day & 15.5 & 18.8 & 13.3 & 14.5 & 2.15 & 0.17 & 0.48 & 0.69 \\
\hline time, min/day & 373 & 373 & 374 & 302 & 49.5 & 0.98 & 0.90 & 0.21 \\
\hline time, $\min / \mathrm{n}$ & 25.3 & 20.4 & 27.7 & 21.7 & 2.87 & 0.11 & 0.44 & 0.10 \\
\hline time, $\mathrm{min} / \mathrm{g} \mathrm{DM}$ & 0.26 & 0.24 & 0.23 & 0.20 & 0.013 & 0.39 & 0.15 & 0.21 \\
\hline
\end{tabular}

${ }^{1}$ see Table $2 ;{ }^{2}$ SE - standard error; ${ }^{3}$ DM - dry matter

and SP $(P \leq 0.02)$ but not different between SP and LP. Eating time, bouts and rate of meadow hay and chopped dehydrated lucerne was not affected by processing method of cereals, except for greater eating frequency of chopped lucerne in GR as compared to SP $(P=0.02)$. Total eating time averaged $142 \mathrm{~min} /$ day and was different only between GR and SP; total eating time was longer $(P=0.05)$ and eating time per bout tended $(P=0.06)$ to be longer for GR as compared to SP. As a result, overall eating rate tended $(P=0.08)$ to be slower for GR in comparison to SP. Rumination parameters were not affected by treatment with exception to tendency $(P=0.10)$ to longer rumination time per bout (min/bout) for SP in comparison to LP.

Despitehugenumericaldifferencesincoefficients of nutrient digestibility between treatments (e.g., 55, $52,47,50 \%$ for NDF digestibility for GR, SF, SP and LP, respectively) initial statistical analysis showed no effect of treatment on the digestibility of either analysed nutrient $(P \geq 0.17$; data not presented). This was a result of huge variations in digestibility coefficients between animals and also within animals between periods. Additionally, a huge day to day-variation in hay intake (e.g., $663 \pm 181 \mathrm{~g}$ of DM for animal No. 3 in $3^{\text {th }}$ period of the study; mean \pm SD) was observed. This resulted not only in day to day-variation in DM intake but also unstructured-tostructured feed ratio. Since this could be not related to treatments, but treated simply a result of excessive intake of concentrates in the diet or disturbing the piece of animals by visitors, we decided to use total DM intake and unstructured-to-structured feed ratio in the statistical model, as covariates, to account for aforementioned observations. After including those covariates in the statistical model, a greater digestibility of $\operatorname{ADF}(P=0.05)$ and a tendency $(P \leq 0.08)$ to greater DM and NDF digestibility for GR in comparison to SP were found (Table 5). It should be noted, as already mentioned, that these results may not be solely result of the treatment, but could also only indicate an effect of the level of roughage intake. Data on feeding behaviour and rumination were also re-analysed with total DM intake and unstructured-to-structured feed ratio included in the statistical model; however, results were almost the same when analysed without covariates in the model as with covariates and those effects were 
Table 5. Effect of processing method of cereals on apparent total tract nutrient digestibility, \%

\begin{tabular}{|c|c|c|c|c|c|c|c|c|}
\hline \multirow{2}{*}{ Indices } & \multicolumn{4}{|c|}{ Treatment $^{1}$} & \multirow{2}{*}{$\mathrm{SE}^{2}$} & \multicolumn{3}{|l|}{ Contrast } \\
\hline & $\overline{G R}$ & SF & SP & LP & & GR vs SF & GR vs SP & SP vs LP \\
\hline Dry matter & 70.3 & 69.9 & 66.6 & 66.5 & 1.11 & 0.26 & 0.06 & 0.50 \\
\hline Organic matter & 59.4 & 58.3 & 53.2 & 55.2 & 1.82 & 0.45 & 0.12 & 0.94 \\
\hline Crude ash & 47.0 & 45.3 & 40.2 & 39.8 & 2.24 & 0.47 & 0.13 & 0.58 \\
\hline Crude protein & 47.5 & 46.7 & 39.6 & 37.7 & 3.58 & 0.75 & 0.27 & 0.63 \\
\hline $\mathrm{NDF}^{1}$ & 54.9 & 52.4 & 46.8 & 49.7 & 2.23 & 0.29 & 0.08 & 0.93 \\
\hline $\mathrm{ADF}^{1}$ & 54.6 & 50.7 & 46.9 & 50.2 & 2.02 & 0.14 & 0.05 & 0.87 \\
\hline
\end{tabular}

${ }^{1}$ see Table $2 ;{ }^{2}$ SE - standard error

not significant for most of the analysed parameters $(P \geq 0.05)$. Therefore, results of initial statistical analysis for those parameters are presented.

\section{Discussion}

In this study, we hypothesized that processing method of cereals would affect feed intake, eating behaviour, rumination and nutrient digestibility in nyala antelope - a species classified as an intermediate feeding ruminant (Gagon and Chew, 2000). Specifically, we expected that: 1 . SF will result in longer and more frequent eating than GR and this will positively affect gastrointestinal tract functioning in nyala, as observed by greater structured feed intake, rumination time and nutrient digestibility; 2 . pelleting of cereals will result in shorter eating time and less frequent eating than GR that will have a negative impact on gastrointestinal tract functioning in nyala, and thus structured feed intake, rumination time and nutrient digestibility; and 3. negative consequences of pelleted cereals usage can be mitigated by increasing pellet size.

In nature, ruminants spend a lot of time foraging that is more or less uniformly distributed over a day (Hofmann, 1989; Van Soest, 1996). Therefore, longer and more frequent eating could potentially allow for better coverage of behavioural needs of this group of animals in captivity. In contradiction to our hypothesis, the basal diet with SF was eaten faster than the basal diet with GR, most likely due to greater size of SF than GR grains and thus easier consumption; however, because cereals were mixed with fruits and vegetables, ground cereals bound to those high moisture feeds limiting selective intake of cereals, and apparently slowing down the basal diet intake (Figure 1). Higher unstructured-to-structured feed ratio for SF in comparison to GR, due to numerically greater basal diet intake and numerically lower hay intake, may also indicate greater palatability of SF in comparison to GR, suggesting - on the other hand - that the 'dusty' consistency of GR could be unattractive for the animals. However, SF is known to increase the rate of starch fermentation in the rumen (López-Soto et al., 2014). This may result in ruminal $\mathrm{pH}$ drop below optimal for the rumen functioning, lower efficiency of ruminal fibre digestion, and, in consequence, lower structured feed intake (Jaakkola and Huhtanen, 1993; Plaizier et al., 2008). In dairy cows, the use of SF increased starch digestibility but decreased fibre digestibility in the total digestive tract (Yu et al., 1998; Zhong et al., 2008). In the current study, SF did not result in lower structured feed intake or fibre digestibility but altered structured-to-unstructured ratio of actually consumed feeds suggesting a negative impact of SF on the gastrointestinal tract functioning in nyala.

Previous studies showed a negative impact of pelleting of concentrates on organic matter and fibre digestibility in sitatunga and addax antelopes (Górka et al., 2016; Przybyło et al., 2017). Furthermore, pelleted concentrates were eaten faster and less frequently than ground concentrates (Górka et al., 2016). Results of the current study confirmed those observations. Nevertheless, it is worth mentioning that the results of previous studies were confounded by different ingredient composition of pelleted and non-pelleted concentrates (Górka et al., 2016; Przybyło et al., 2017). In the current study, cereals originated from the same batches and ingredient composition of the mixture of cereals was the same for all treatments. Therefore, the observed impact of pelleted feed on eating behaviour and nutrient digestibility in nyala can be attributed solely to the pelleting process; however, some differences in chemical composition between GR and other treatments were observed (lower fibre content for GR in comparison to SF, SP and LP). Moisture, pressure and heat treatment could affect chemical composition of processed cereals. Higher fibre content in steam-flaked and pelleted cereals, however, is unlikely to explain observed differences in eating behaviour between treatments since fibre intake did not differ between treatments. 
As already mentioned, faster and less frequent eating of pelleted feeds as compared to non-pelleted ones has been already shown (Waghorn and Reid, 1983; Górka et al., 2016). It has been also found that pelleting of concentrates increases the rate of ruminal fermentation, in comparison to finely ground concentrates, leading to lower ruminal $\mathrm{pH}$ (Castrillo et al., 2013). Especially fibre fermenting bacteria are sensitive to low ruminal $\mathrm{pH}$ (Plaizier et al., 2008). Less frequent and more abundant meals in combination with more rapid ruminal fermentation of starch in the rumen explains negative impact of pelleting on fibre digestibility in the current study. Combined, results of the current and previous studies (Górka et al., 2016; Przybyło et al., 2017) suggest that pelleting of cereals is the least desirable method of their processing for captive ruminants.

Castrillo et al. (2013) proposed that larger diameter size of pellet allows for more uniform pattern of daily feed intake of concentrates by high-grain fed cattle and that this results in lower probability of ruminal $\mathrm{pH}$ drop below optimal for the rumen functioning. Therefore, we hypothesized that a negative impact of pelleted cereals on gastrointestinal functioning in nyala (if observed) may be reduced by increasing the size of the pellet. Although eating time of the basal diet was longer for LP than SP by an average of (only) $4 \mathrm{~min} /$ day, there was no effect of pellet size on nutrient digestibility (this was lower for both LP and SP as compared to GR). Nevertheless, taking into account that eating rates of basal diet with LP and SP were comparable but eating time was longer for LP diet, animals spent more time for consuming, biting and chewing LP. Physical structure of feeds that ensures adequate mechanical stimulus and results in behavioural needs satisfaction plays an important role in captive ruminants nutrition and may prevent oral stereotypies (Schaub et al., 2004). However, there is scarcity of studies investigating tongue and mouth muscles involvement in process of different concentrates consumption as well as their correlation with saliva production and rumen environment. The time animals spend foraging can be considered also as an important problem in zoo ruminant nutrition; in captivity this activity is reduced at least several times in comparison to what is observed in natural conditions (Rose and Robert, 2013). Enlargement of pellet size may be helpful in increasing the time of unstructured feed intake but probably does not reduce the negative impact of pelleted cereals on gastrointestinal tract functioning, and did not affect the overall daily eating time in the present study.
In general, processing of cereals used in the basal diet had the most pronounced impact on eating behaviour in the current study. This was a result of high proportion of unstructured feeds $(46.1 \pm$ $1.69 \%$; DM basis) in the actually consumed diet. High proportion of unstructured feed in the diet for captive ruminants, due to overfeeding cereal-based concentrates, fruits and vegetables as well as unwilling intake of grass hay by browsing and intermediate feeding ruminants, has been shown previously (Schilcher et al., 2013; Taylor et al., 2013; Górka et al., 2016). Such a nutritional situation is commonly criticized and considered as the most important reason for a short longevity of wild ruminants in captivity (Lintzenich and Ward, 1997; Clauss and Dierenfeld, 2008). Additionally, in this study huge day to day variation of hay intake was observed, further suggesting negative consequences of high intake of unstructured feeds on the gastrointestinal tract functioning of nyala.

Based on the results of the current study, GR could be considered as the most desired method of processing of cereals for nyala (and most likely also for other captive ruminants), based on longer time spent on eating this treatment $(157 \mathrm{~min} /$ day $)$. It is also worth mentioning that, in the current study, it was hypothesized that the most favourable processing method of concentrates will result in greater structured feed intake; however, there was no effect of processing method of cereals on structured feeds intake and eating time or rate of those feeds, except some changes in lucerne eating behaviour. Furthermore, given the absolute amount of time spent on eating by the nyala in the present study (2-3 h/day) and the moderate increase of this time by the GR treatment by about $25 \mathrm{~min}$ as compared to LP, it is evident that in order to make the feeding behaviour in captivity more similar to the wild, other methods than cereal processing need to be considered. Most particularly, the diet of a generally lower energy density with a higher proportion of structural components appears warranted. With a time budget of a maximum of 2-3 $\mathrm{h}$ /day spent on eating in the present study, the animals were not behaviourally constrained to consume more feed, or to eat slowly. For example, in the natural environment mountain nyala (Tragelaphus buxtoni) spends about $8 \mathrm{~h}$ on feeding (Tadesse and Kotler, 2013). In such diet of lower energy content, cereals might not be a suitable ingredient. Another way to increase total time spent on eating by captive ruminants could be more frequent feeding over a day (Hummel et al., 2006). More studies are 
needed to determine possible ways of reduction and removal of concentrates from diets for captive ruminants.

\section{Conclusions}

The study demonstrated that processing method of concentrates affects eating patterns of nyala without impact on feed intake. Grinding can be considered as the most desired and steam-flaking and pelleting as the less desired methods of concentrate processing for nyala; however, negative consequences of pelleted cereals use can be partially mitigated by increasing the pellet size. It was also shown that in case of feeding a diet containing a substantial amount of non-structural materials, the time spent on feeding, deviates dramatically from that observed in the wild. Results presented in the current study could be used for evaluation of diets for other captive ruminants and transferred to other species, especially browsing and intermediate feeding type ruminants. Overfeeding with cereal-based concentrates, fruits and vegetables is still an issue in zoo ruminants nutrition and should be avoided.

\section{Acknowledgments}

The authors would like to thank Silesian Zoological Garden staff and Małgorzata Drąg for help with sample collection and assistance during the study.

\section{References}

Bertipaglia L.M.A., Fondevila M., van Laar H., Castrillo C., 2010. Effect of pelleting and pellet size of a concentrate for intensively reared beef cattle on in vitro fermentation by two different approaches. Anim. Feed Sci. Technol. 159, 88-95, https://doi. org/10.1016/j.anifeedsci.2010.05.010

Castrillo C., Mota M., Van Laar H., Martin-Tereso J., Gimeno A., Fondevila M., Guada J.A., 2013. Effect of compound feed pelleting and die diameter on rumen fermentation in beef cattle fed high concentrate diets. Anim. Feed Sci. Technol. 180, 34-43, https://doi.org/10.1016/j.anifeedsci.2013.01.004

Clauss M., Dierenfeld E.S., 2008. The nutrition of "browsers". In: M.E. Fowler, R.F. Miller (Editors). Zoo and Wild Animal Medicine. Current Therapy. Volume 6. Saunders Elsevier. St. Louis, MO (USA), pp. 444-454, https://doi.org/10.1016/B978141604047-7.50058-0

Clauss M., Kienzle E., Hatt J.-M., 2003. Feeding practice in captive wild ruminants: peculiarities in the nutrition of browsers/concentrate selectors and intermediate feeders. A review. In: A. Fidgett, M. Clauss, U. Ganslosser, J.-M. Hatt, J. Nijboer (Editors). Zoo Animal Nutrition. Volume 2. Filander Verlag. Fürth (Germany), pp. 27-52

Gagnon M., Chew A.E., 2000. Dietary preferences in extant African Bovidae. J. Mammal. 81, 490-511, https://doi.org/10.1644/15451542(2000)081<0490:DPIEAB>2.0.CO;2
Gattiker C., Espie I., Kotze A., Lane E.P., Codron D., Clauss M., 2014. Diet and diet-related disorders in captive ruminants at the national zoological gardens of South Africa. Zoo Biol. 33, 426432, https://doi.org/10.1002/zoo.21150

Górka P., Castillo-Lopez E., Joy F., Chibisa G.E., McKinnon J.J., Penner G.B., 2015. Effect of including high-lipid by-product pellets in substitution for barley grain and canola meal in finishing diets for beef cattle on ruminal fermentation and nutrient digestibility. J. Anim. Sci. 93, 4891-4902, https://doi.org/10.2527/ jas.2015-9282

Górka P., Przybyło M., Kański J., Kloska A., 2016. Effect of pelleted cereal-based feed used in the diet on feed intake, eating behaviour, rumination and nutrient digestibility in antelope sitatunga (Tragelaphus spekii). J. Anim. Feed Sci. 25, 125-133, https:// doi.org/10.22358/jafs/65572/2016

Hofmann R.R., 1989. Evolutionary steps of ecophysical adaptation and diversification of ruminants: a comparative view of their digestive system. Oecologia 78, 443-457, https://doi.org/10.1007/ BF00378733

Hummel J., Nogge G., Clauss M., Nørgaard C., Johanson K., Nijboer J., Pfeffer E., 2006. Energy supply of the okapi in captivity: fermentation characteristics of feedstuffs. Zoo Biol. 25, 251-266, https://doi.org/10.1002/zoo.20101

Jaakkola S., Huhtanen P., 1993. The effects of forage preservation method and proportion of concentrate on nitrogen digestion and rumen fermentation in cattle. Grass Forage Sci. 48, 146-154, https://doi.org/10.1111/j.1365-2494.1993.tb01847.x

Lintzenich B.A., Ward A.M., 1997. Hay and pellet ratios: considerations in feeding ungulates. Nutrition Advisory Group Handbook. Fact Sheet 006, pp. 12

López-Soto M.A., Barreras A., Calderón-Cortés J.F. et al., 2014. Influence of processing of barley grain on characteristics of digestion, ruminal fermentation and digestible energy of diet in lactating cows. Iran. J. App. Anim. Sci. 4, 477-484

McCusker S., Shipley L.A., Tollefson T.N., Griffin M., Koutsos E.A., 2011. Effects of starch and fibre in pelleted diets on nutritional status of mule deer (Odocoileus hemionus) fawns. J. Anim. Physiol. Anim. Nutr. 95, 489-498, https://doi.org/10.1111/ j.1439-0396.2010.01076.x

Plaizier J.C., Krause D.O., Gozho G.N., McBride B.W., 2008. Subacute ruminal acidosis in dairy cows: The physiological causes, incidence and consequences. Vet. J. 176, 21-31, https://doi. org/10.1016/j.tvjl.2007.12.016

PN-EN 1233:2000P. Water quality - Determination of chromium - Atomic absorption spectrophotometric methods.

Przybyło M., Górka P., Tyl P., Kański J., KloskaA., 2017. Effect of pelleted cereal-based feed use for addax antelope (Addax nasomaculatus) on feed intake and nutrient digestibility. J. Anim. Feed Sci. 26, 348-353, https://doi.org/10.22358/jafs/78512/2017

Razzaghi A., Larsen M., Lund P., Weisbjerg M.R., 2016. Effect of conventional and extrusion pelleting on in situ ruminal degradability of starch, protein, and fibre in cattle. Livest. Sci. 185, 97-105, https://doi.org/10.1016/j.livsci.2016.01.017

Rose P., Robert R., 2013. Evaluating the activity patterns and enclosure usage of a little-studied zoo species, the sitatunga (Tragelaphus spekii). J. Zoo Aquar. Res. 1, 14-19. https://doi.org/10.19227/ jzar.v1i1.12

Schaub D., Clauss M., Flach E.J., Wettstein H.R., Tack C., Hatt J.-M., 2004. Influence of physical and chemical composition of diet on oral stereo-typies in captive giraffes (Giraffa camelopardalis). In: Proceedings of the European Association of Zoo and Wildlife Veterinarians (EAZWV). 5, 27-28 
Schilcher B., Baumgartner K., Geyer H., Liesegang A., 2013. Investigations on rumen health of different wild ruminants in relation to feeding management. J. Zoo Aquar. Res. 1, 28-30, https:// doi.org/10.19227/jzar.v1i1.14

Tadesse S.A., Kotler B.P., 2013. Habitat use by mountain nyala Tragelaphus buxtoni determined using stem bite diameters at point of browse, bite rates, and time budgets in the Bale Mountains National Park, Ethiopia. Curr. Zool. 59, 707-717, https://doi.org/10.1093/czoolo/59.6.707

Taylor L.A., Schwitzer C., Owen-Smith N., Kreuzer M., Clauss M., 2013. Feeding practices for captive greater kudus (Tragelaphus strepsiceros) in UK collections as compared to diets of free-ranging specimens. J. Zoo Aquar. Res. 1, 7-13, https:// doi.org/10.19227/jzar.v1i1.18

Waghorn G.C., Reid C.S.W., 1983. Rumen motility in sheep and cattle given different diets. New Zeal. J. Agric. Res. 26, 289-295, https://doi.org/10.1080/00288233.1983.10427032
Van Soest P.J., 1996. Allometry and ecology of feeding behavior and digestive capacity in herbivores: a review. Zoo Biol. 15, 455-479, https://doi.org/10.1002/(SICI)10982361(1996)15:5<455::AID-ZOO3>3.0.CO;2-A

Yu P., Huber J.T., Santos F.A.P., Simas J.M., Theurer C.B., 1998. Effects of ground, steam-flaked and steam-rolled corn grains on performance of lactating cows. J. Dairy Sci. 81, 777-783, https://doi.org/10.3168/jds.S0022-0302(98)75634-6

Zhong R.Z., Li J.G., Gao Y.X., Tan Z.L, Ren G.P., 2008. Effects of substitution of different levels of steam-flaked corn for finely ground corn on lactation and digestion in early lactation dairy cows. J. Dairy Sci. 91, 3931-3937, https://doi.org/10.3168/ jds.2007-0957 